\title{
Nystatin effect on chlorhexidine efficacy against Streptococcus mutans as planktonic cells and mixed biofilm with Candida albicans
}

\author{
Maria Eduarda Lanes Baldino ${ }^{1} \cdot$ Renata Medina-Silva ${ }^{2}$ Juliana Sumienski ${ }^{2} \cdot$ Maria Antonia Figueiredo $^{1}$. \\ Fernanda Gonçalves Salum ${ }^{1} \cdot$ Karen Cherubini ${ }^{1,3}$
}

Received: 9 October 2020 / Accepted: 17 June 2021 / Published online: 23 June 2021

(c) The Author(s), under exclusive licence to Springer-Verlag GmbH Germany, part of Springer Nature 2021

\begin{abstract}
Objective The aim of this study was to evaluate the effect of nystatin on the efficacy of chlorhexidine against Streptococcus mutans in planktonic cells and mixed biofilm with Candida albicans.

Material and methods S. mutans ATCC 25,175 in suspension and also combined with C. albicans ATCC 18,804 in biofilm were cultured. Minimum inhibitory concentration (MIC), crystal violet colorimetric assay, and colony-forming unit counting (CFUs/mL) were performed.

Results An increased MIC of chlorhexidine against $S$. mutans was observed when the drugs were administered mixed in a single formulation and with time intervals in between, except for the 30-min interval. The biofilm optical density (OD) in treatments using chlorhexidine and nystatin combined did not significantly differ from chlorhexidine alone. Either in biofilm colorimetric assay or determination of CFUs, the combined treatments with nystatin administered before chlorhexidine had less effect on chlorhexidine efficacy.

Conclusions Nystatin interferes with the action of chlorhexidine against $S$. mutans. The antimicrobial effectiveness of the combined drugs depends on their concentration, time interval used, and the planktonic or biofilm behavior of the microorganisms.

Clinical relevance In view of the great number of patients that can receive a prescription of chlorhexidine and nystatin concomitantly, this study contributes to the knowledge about the effect of the combined drugs. Given the high prevalence of prescriptions of chlorhexidine and nystatin in dentistry, dental professionals should be aware of their possible antagonistic effect.
\end{abstract}

Keywords Chlorhexidine $\cdot$ Nystatin $\cdot$ Biofilms $\cdot$ Drug interactions $\cdot$ Inpatients $\cdot$ Immunocompromised host

\section{Introduction}

With increase in life expectancy, a substantial number of people experience immunodeficiency worldwide. This happens mostly as a consequence of therapies for cancer,

Karen Cherubini

karen.cherubini@pucrs.br

1 Post-Graduate Program, School of Health and Life Sciences, Pontifical Catholic University of Rio Grande Do Sul, Porto Alegre, RS, Brazil

2 Laboratory of Immunology and Microbiology, School of Health and Life Sciences, Pontifical Catholic University of Rio Grande Do Sul, Porto Alegre, RS, Brazil

3 Serviço de Estomatologia - Hospital São Lucas, PUCRS, Av. Ipiranga, 6690 Sala 231, Porto Alegre, RS CEP 90610-000, Brazil autoimmune diseases, and organ transplantation, but is also associated with HIV. Opportunistic infections are a major concern in immunocompromised patients, where the oral cavity is an important source of infection, since it is colonized by various microorganisms, including viruses, protozoa, fungi, archaea, and bacteria [1]. Because of the risk of developing systemic complications of opportunistic oral infections, the prescription of antimicrobial mouthwashes is often required [2].

Chlorhexidine is a cationic bisbiguanide, which is considered one of the most commonly prescribed antimicrobials due to its broad spectrum against gram-negative and gram-positive bacteria and some mycetes [3, 4]. It is available as acetate, hydrochloride, and digluconate salts. The first two are poorly soluble in water, and the last is water soluble and has been indicated in routine dental procedures as a mouthwash, gel, and spray $[4,5]$. Chlorhexidine has 
been prescribed in oral care for various purposes, such as chemical control of dental biofilm, root canal irrigation, and treatment of oral infections. These include infections affecting xerostomic patients, who are at high risk of periodontal disease and dental caries, where the latter mainly involves Streptococcus mutans $[3,4,6,7]$. In addition, it can be considered an alternative antifungal agent to treat oral candidiasis [8]. Chlorhexidine has also been prescribed to reduce the risk of developing ventilator-associated pneumonia in critical care patients [9].

Nystatin, in turn, is a polyene antifungal that is effective against Candida, Cryptococcus, Aspergillus, Histoplasma, and Blastomyces [10,11]. The drug is available in the form of cream, tablets, suspension, mouthwash, gel, and lozenges [12]. Nystatin is limited to topical use because of insignificant oral absorption and also systemic toxicity related to intravenous administration. It is prescribed to treat oral candidiasis, where an overgrowth of Candida spp. is involved, especially C. albicans [12-14]; it plays an important role in the prophylaxis of oral and systemic candidiasis in newborns, infants, and immunocompromised patients [13].

Barkvoll and Attramadal [15] evaluated, in vitro, the effect of mixed chlorhexidine and nystatin in a single formulation against $C$. albicans and found that when combined, these drugs exhibited an antagonistic interaction, forming an ineffective low-solubility salt. Some authors, however, recommend the simultaneous use of the two drugs to treat denture-related stomatitis [16]. Recently, Scheibler et al. [17] demonstrated, in vitro, that the combination of chlorhexidine and nystatin seemed to impair the efficacy of the drugs against $C$. albicans, especially in biofilm.

Chlorhexidine has been widely prescribed worldwide, and, despite the controversies regarding this issue, patients may be given prescriptions of chlorhexidine and nystatin at the same time. This is a major concern regarding hospitalized immunocompromised patients [13], especially those in the intensive care unit (ICU) and geriatric ones, who often develop oral candidiasis, meanwhile having difficulty with maintaining oral hygiene by themselves. Particularly, the situation in the ICU, with high risk of systemic complications of opportunistic infections associated with oral biofilm, which are also favored by hyposalivation, often demands prescriptions of nystatin and chlorhexidine, since these are gold-standard antimicrobial mouthwashes for Candida spp. and bacteria, respectively $[2,4,8]$. However, the empirical use of the combination of these drugs, with no established protocols to prevent possible interactions, might impair treatment efficacy, increasing cost and the patient's time in the unit. Even though studies evaluating the effectiveness of the drug combination against $C$. albicans have already been conducted, the literature lacks investigations focusing on the effect of combined chlorhexidine and nystatin on the antibacterial activity of chlorhexidine. Therefore, the present study aimed to investigate the effect of nystatin on the antimicrobial efficacy of chlorhexidine against $S$. mutans in planktonic cells and mixed biofilm with Candida albicans.

\section{Materials and methods}

\section{Study design}

The broth microdilution assay was performed according to Clinical and Laboratory Standards Institute guidelines [18, 19], to determine the minimum inhibitory concentration (MIC) of chlorhexidine against $S$. mutans, when combined with nystatin. The efficacy of chlorhexidine and nystatin in combination was also examined in a mixed biofilm of $S$. mutans and $C$. albicans. Figure 1 describes schematically the procedures carried out in the study.

\section{Microbial isolates}

S. mutans ATCC 25,175 was recovered in brain heart infusion broth (BHI, Oxoid, Basingstoke, Hampshire, UK) and grown on BHI agar plates, at $37{ }^{\circ} \mathrm{C}$ for 48 h. C. albicans ATCC 18,804 was recovered in $2 \%$ yeast extract-peptonedextrose (YPD; Himedia, Mumbai, India; 2\% D-glucose, $2 \%$ peptone, $1 \%$ yeast extract) broth and grown on YPD agar plates at $30{ }^{\circ} \mathrm{C}$ for $48 \mathrm{~h}$.

\section{Minimum inhibitory concentration assay}

The antimicrobial agents used were aqueous 20\% chlorhexidine digluconate (Sigma-Aldrich, St. Louis, MO, USA) and $2 \mathrm{mg} / \mathrm{mL}$ stock solution of nystatin (Sigma-Aldrich) prepared in dimethyl sulfoxide (DMSO; Dinâmica Química Contemporânea Ltda., São Paulo, SP, Brazil) [20]. The inoculum of $S$. mutans was adjusted to 0.5 McFarland turbidity $\left(1.5 \times 10^{8} \mathrm{CFU} / \mathrm{mL}\right)$ [21]. The suspension density was also determined with a spectrophotometer (Genesys 20, Thermo Scientific, Waltham, MA, USA) at $600 \mathrm{~nm}$, with the final inoculum adjusted to an absorbance of 0.11-0.14. Concentration, viability, and purity of the inoculum were evaluated [17].

A 2- $\mu \mathrm{L}$ aliquot of the inoculum suspension was added to each well containing $100 \mu \mathrm{L}$ of BHI broth in the 96-well microplate. Next, the drugs were added by using a two-fold serial dilution where concentrations ranged from 0.5 to $64 \mu \mathrm{g} / \mathrm{mL}(0.5,1,2,4,8,16,32$, and $64 \mu \mathrm{g} / \mathrm{mL})$ for chlorhexidine and 0.25 to $32 \mu \mathrm{g} / \mathrm{mL}(0.25,0.5,1,2,4,8,16$, and $32 \mu \mathrm{g} / \mathrm{mL}$ ) for nystatin [18]. The same process was repeated considering the different treatments, with 10 replicates for each one, where $S$. mutans was treated with (1) chlorhexidine; (2) nystatin; (3) chlorhexidine and 30 min later with nystatin; (4) nystatin and 30 min later with chlorhexidine; 


\section{BROTH MICRODILUTION ASSAY}

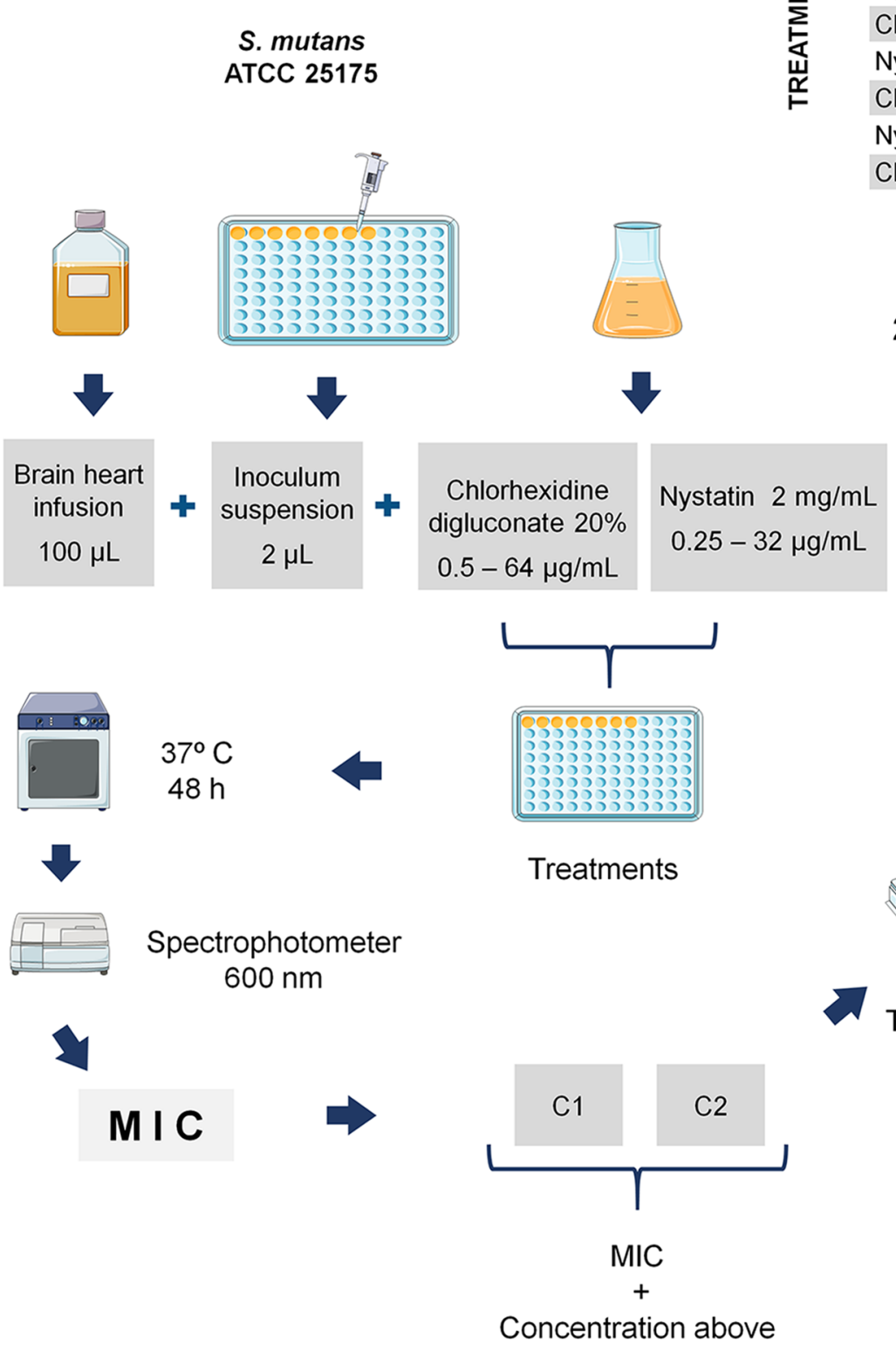

Chlorhexidine $(n=10)$

\section{Nystatin $(n=10)$}

Chlorhexidine $/ 30 \mathrm{~min} /$ nystatin $(n=10)$

Nystatin/30min/chlorhexidine $(n=10)$

Chlorhexidine/1 $\mathrm{min} /$ nystatin $(n=10)$

Nystatin/2min/chlorhexidine $(n=10)$

Chlorhexidine/10min/nystatin $(n=10)$

Nystatin/10 min/chlorhexidine $(n=10)$

Chlorhexidine/nystatin single formulation $(n=10)$

\section{BIOFILM ASSAY}

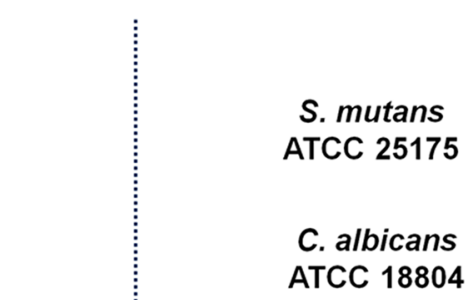

Fig. 1 Schematic representation of the study procedures. The broth microdilution assay was performed to determine the minimum inhibitory concentration (MIC) of chlorhexidine against $S$. mutans when combined with nystatin (1). The efficacy of chlorhexidine and nysta-

(5) chlorhexidine and 1 min later with nystatin; (6) nystatin and 2 min later with chlorhexidine; (7) chlorhexidine and 10 min later with nystatin; (8) nystatin and 10 min later with chlorhexidine; and (9) chlorhexidine and nystatin in a single formulation.

The time intervals between the administrations of the drugs were based on a previous study [17]. The 30-min tin in combination was also examined in a mixed biofilm of $S$. mutans and $C$. albicans (2). Parts of the figure were drawn by using Servier Medical Art templates, which are licensed under a Creative Commons Attribution 3.0 Unported License (https://smart.servier.com)

interval was based on the recommended time interval between chlorhexidine and fluoride toothpaste use [22]. The interval of $1 \mathrm{~min}$ and $2 \mathrm{~min}$, in turn, corresponded to the recommended mouthwash time for chlorhexidine and nystatin, respectively. And the interval of $10 \mathrm{~min}$ was chosen as an intermediate time. Chlorhexidine and nystatin in a single formulation was a mixture of chlorhexidine and nystatin 
used to administer the two drugs simultaneously, which was prepared immediately before use [17].

After the treatments, the plates were incubated at $37{ }^{\circ} \mathrm{C}$ for $48 \mathrm{~h}$. Afterwards, the optical density (OD) of the $S$. mutans suspension was determined with a spectrophotometer (SpectraMax 190) at $600 \mathrm{~nm}$. MIC criterion was the lowest concentration of the test agent capable of reducing bacterial growth by $70 \%$.

\section{Biofilm formation}

C. albicans was grown in $2 \%$ YPD at $30{ }^{\circ} \mathrm{C}$ and $S$. mutans in BHI broth in a microaerophilic chamber at $37{ }^{\circ} \mathrm{C}$, both for $16 \mathrm{~h}$. Next, cultures were centrifuged ( $8000 \mathrm{rpm}, 5 \mathrm{~min})$, and the supernatant was removed. The pellet was resuspended in $1 \mathrm{~mL}$ of sterile phosphate-buffered saline (PBS, $\mathrm{pH}$ 7.2) and washed twice and the concentration adjusted to $0.800-1$ OD $[17,23]$ using a spectrophotometer (Genesys 20) at $570 \mathrm{~nm}$. Equal volumes of each bacterial and fungal suspension (75 $\mu \mathrm{L}$ ) were added to the well, in a flat-bottom 96-well plate, and incubated at $37^{\circ} \mathrm{C}$ for $2 \mathrm{~h}$ to promote adherence of the cells to the surface [24]. The wells were then washed twice with sterile PBS to remove the non-adherent cells, and 150 $\mu \mathrm{L}$ of BHI were added. The plate was incubated at $37^{\circ} \mathrm{C}$ for $48 \mathrm{~h}[25,26]$. Afterwards, non-adherent cells were removed, the plate was examined under light microscopy $(400 \times$ magnification; Light Microscope CX31, Olympus) to verify the occurrence of $S$. mutans and $C$. albicans cells in the biofilms, and the treatments were then applied.

\section{Biofilm treatment}

Biofilm received the different treatments tested on planktonic samples, but with only two concentrations for each drug. The concentrations of chlorhexidine and nystatin used were equal to or just above the MIC in each group. The MIC used for nystatin was based on Scheibler et al. [17]. All assays were performed with 10 replicates.

After the treatments, the biofilm plates with the drugs were incubated at $37{ }^{\circ} \mathrm{C}$ for $48 \mathrm{~h}$. Later, the biofilm was gently washed twice with PBS, stained with $0.1 \%$ crystal violet for $10 \mathrm{~min}$, washed with PBS, and fixed with $96 \%$ ethanol. The crystal violet $\mathrm{OD}$, which indicates the concentration of viable cells in the biofilms, was determined with a spectrophotometer (SpectraMax 190) at $570 \mathrm{~nm}$. Also, the coefficient of drug interaction (CDI) was calculated according to the formula $\mathrm{CDI}=\mathrm{AB} /(\mathrm{AxB})$, where $\mathrm{AB}$ is the ratio of the treatment combination to the control and $\mathrm{A}$ or $\mathrm{B}$ is the ratio of the single treatment to the control. CDI greater than 1 indicates that the drugs are antagonistic [27].

Since the crystal violet colorimetric assay determines the total biomass of the mixed-species biofilm, without distinguishing S. mutans from C. albicans, CFU counting was also performed [28]. The biofilm was washed with sterile PBS; cells were resuspended in $200 \mu \mathrm{L}$ of PBS and subjected to ultrasound for $10 \mathrm{~min}$, followed by pipetting up and down. Subsequently, cell suspensions underwent serial dilution and were plated (10 $\mu \mathrm{L}$ drops) on BHI agar with amphotericin B $(0.025 \mathrm{mg} / \mathrm{mL})$ and incubated at $37^{\circ} \mathrm{C}$ for bacterial growth; the same plating was done on Sabouraud dextrose agar (SDA; Himedia) with chloramphenicol $(0.005 \mathrm{mg} / \mathrm{mL})$ at $30{ }^{\circ} \mathrm{C}$ for yeast growth. The incubation period was $48 \mathrm{~h}[23$, 29]. Colonies formed were then counted, and $\mathrm{CFU} / \mathrm{mL}$ was determined for $S$. mutans and $C$. albicans, for the different biofilm treatments. The assay was performed in triplicate.

\section{Statistical analysis}

Data were analyzed using descriptive statistics and one-way ANOVA complemented by Dunnett's T3 multiple comparisons test in SPSS 21.0, at a significance level of 5\%.

\section{Results}

\section{Chlorhexidine MIC analysis}

Chlorhexidine alone and in the combinations with a 30-min interval was capable of reducing bacterial growth by $70 \%$ at the lowest concentration tested (MIC $\leq 0.50 \mu \mathrm{g} / \mathrm{mL}$ ). The other groups, either with different intervals between the drugs or single formulation, exhibited a higher MIC, where chlorhexidine/1 min/nystatin had the highest mean $(1 \mu \mathrm{g} /$ $\mathrm{mL}$ ) (Table 1).

\section{S. mutans suspensions}

Table 2 exhibits the OD for $S$. mutans suspensions according to the different treatments (ANOVA, Dunnett's T3, $\alpha=0.05)$. At higher concentrations $(\mathrm{C} 2, \mathrm{C} 3)$, chlorhexidine

Table 1 Minimum inhibitory concentration (MIC) for chlorhexidine in broth microdilution, according to the treatment applied

\begin{tabular}{lllll}
\hline \multirow{2}{*}{ Treatment } & \multicolumn{4}{l}{ MIC of chlorhexidine $(\mu \mathrm{g} / \mathrm{mL})$} \\
\cline { 2 - 5 } & Mean & SD & Minimum & Maximum \\
\hline Chlorhexidine & $\leq 0.50$ & 0.00 & $\leq 0.50$ & $\leq 0.50$ \\
Chlorhexidine/30 min/nystatin & $\leq 0.50$ & 0.00 & $\leq 0.50$ & $\leq 0.50$ \\
Nystatin/30 min/chlorhexidine & $\leq 0.50$ & 0.00 & $\leq 0.50$ & $\leq 0.50$ \\
Chlorhexidine/1 min/nystatin & 1.00 & 0.00 & 1.00 & 1.00 \\
Nystatin/2 min/chlorhexidine & 0.55 & 0.16 & $\leq 0.50$ & 1.00 \\
Chlorhexidine/10 min/nystatin & 0.65 & 0.47 & $\leq 0.50$ & 2.00 \\
Nystatin/10 min/chlorhexidine & 0.85 & 0.24 & $\leq 0.50$ & 1.00 \\
Chlorhexidine/nystatin single & 0.55 & 0.16 & $\leq 0.50$ & 1.00 \\
\hline
\end{tabular}

$S D$ standard deviation 


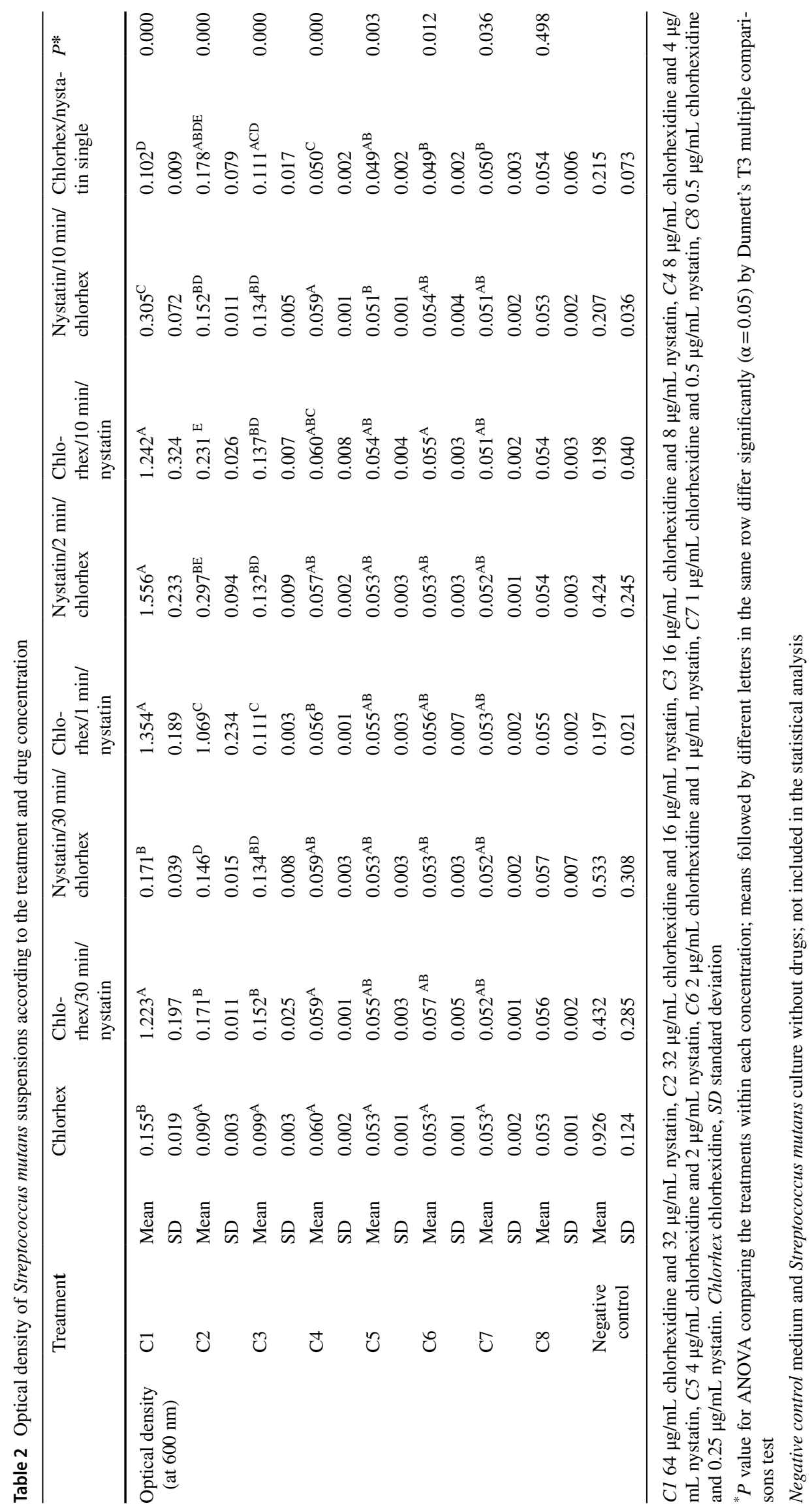


alone exhibited the lowest OD. However, it did not significantly differ from the OD of chlorhexidine/nystatin single formulation. At lower concentrations (C4, C5, C6, C7, C8), the combination of the drugs did not interfere with the effect of chlorhexidine. Still, at these concentrations, the single formulation of chlorhexidine/nystatin exhibited a better effect than chlorhexidine alone. At $\mathrm{C} 1$, an orange-brown precipitate was observed at the bottom of the wells when the drugs were combined, except in chlorhexidine/nystatin single formulation.

\section{S. mutans and C. albicans mixed biofilm}

In biofilm treatments, the chlorhexidine and nystatin combined groups did not significantly differ from chlorhexidine alone at the concentrations tested. However, at $\mathrm{C} 1$, the nystatin/2 min/chlorhexidine group had a significantly lower OD than nystatin alone, and also than the 10-min and 30-min groups. When $\mathrm{C} 2$ was tested, nystatin $/ 2 \mathrm{~min} / \mathrm{chlorhexidine}$ still had a significantly lower OD than nystatin/30 $\mathrm{min} / \mathrm{chlo-}$ rhexidine but did not differ from the other groups (Table 3, ANOVA, Dunnett's T3, $\alpha=0.05$ ). Table 4 presents the CDI for each treatment combination in the biofilm assay, and Fig. 2 shows the comparison of OD between $S$. mutans suspensions and mixed $S$. mutans/C. albicans biofilms.

\section{CFU counts}

Figure 3 displays the $\mathrm{CFU} / \mathrm{mL}$ counts for $S$. mutans and $C$. albicans according to the different treatments. Chlorhexidine alone and nystatin/10 $\mathrm{min} / \mathrm{chlorhexidine} \mathrm{showed} \mathrm{the} \mathrm{lowest}$ counts for $S$. mutans. Nystatin alone displayed significantly
Table 4 Coefficient of drug interaction (CDI) for chlorhexidine and nystatin combinations in the Candida albicans and Streptococcus mutans biofilm assay according to the treatment used

\begin{tabular}{lll}
\hline Treatment & CDI & \\
\cline { 2 - 3 } & $\mathrm{C} 1$ & $\mathrm{C} 2$ \\
\hline Chlorhexidine/30 min/nystatin & 2.105 & 2.272 \\
Nystatin/30 min/chlorhexidine & 1.986 & 2.280 \\
Chlorhexidine/1 min/nystatin & 1.905 & 1.536 \\
Nystatin/2 min/chlorhexidine & 1.695 & 1.452 \\
Chlorhexidine/10 min/nystatin & 2.401 & 2.285 \\
Nystatin/10 min/chlorhexidine & 2.401 & 2.285 \\
Chlorhexidine/nystatin single & 1.570 & 1.517 \\
\hline
\end{tabular}

C1 $2 \mu \mathrm{g} / \mathrm{mL}$ chlorhexidine and $1 \mu \mathrm{g} / \mathrm{mL}$ nystatin, $C 21 \mu \mathrm{g} / \mathrm{mL}$ chlorhexidine and $0.5 \mu \mathrm{g} / \mathrm{mL}$ nystatin

higher bacterial counts than the other groups. Chlorhexidine/ nystatin single formulation exhibited greater $\mathrm{CFU} / \mathrm{mL}$ for $C$. albicans than the other groups.

\section{Discussion}

Our results showed that nystatin affected the MIC value of chlorhexidine against $S$. mutans, where all groups, except the 30-min interval ones, showed an increased MIC. In testing C. albicans instead of S. mutans, Scheibler et al. [17] and Barkvoll and Attramadal [15] also reported that chlorhexidine and nystatin combined resulted in higher MIC values.

In our study, the combination of the drugs with a 30-min interval showed the same MIC as chlorhexidine alone, which
Table 3 Optical density in crystal violet assay of Streptococcus mutans and Candida albicans mixed biofilm according to the treatment

\begin{tabular}{|c|c|c|c|c|c|c|}
\hline \multirow[t]{3}{*}{ Treatment } & \multicolumn{6}{|c|}{ Optical density (at $570 \mathrm{~nm}$ ) } \\
\hline & \multicolumn{2}{|l|}{$\mathrm{C} 1$} & \multicolumn{2}{|l|}{$\mathrm{C} 2$} & \multicolumn{2}{|c|}{ Negative control } \\
\hline & Mean & SD & Mean & SD & Mean & SD \\
\hline Chlorhexidine & $0.180^{\mathrm{ABC}}$ & 0.036 & $0.181^{\mathrm{AB}}$ & 0.050 & 0.416 & 0.074 \\
\hline Nystatin & $0.218^{\mathrm{AC}}$ & 0.044 & $0.228^{\mathrm{AB}}$ & 0.068 & 0.416 & 0.074 \\
\hline Chlorhexidine/30 min/nystatin & $0.210^{\mathrm{A}}$ & 0.031 & $0.240^{\mathrm{AB}}$ & 0.089 & 0.373 & 0.167 \\
\hline Nystatin/30 min/chlorhexidine & $0.199^{\mathrm{AC}}$ & 0.030 & $0.241^{\mathrm{A}}$ & 0.052 & 0.373 & 0.167 \\
\hline Chlorhexidine/1 min/nystatin & $0.161^{\mathrm{BC}}$ & 0.013 & $0.153^{\mathrm{B}}$ & 0.021 & 0.352 & 0.173 \\
\hline Nystatin/2 min/chlorhexidine & $0.143^{\mathrm{B}}$ & 0.014 & $0.144^{\mathrm{B}}$ & 0.014 & 0.352 & 0.173 \\
\hline Chlorhexidine/10 min/nystatin & $0.191^{\mathrm{AC}}$ & 0.027 & $0.192^{\mathrm{AB}}$ & 0.053 & 0.442 & 0.189 \\
\hline Nystatin/10 min/chlorhexidine & $0.191^{\mathrm{AC}}$ & 0.027 & $0.192^{\mathrm{AB}}$ & 0.053 & 0.442 & 0.189 \\
\hline Chlorhexidine/nystatin single & $0.168^{\mathrm{ABC}}$ & 0.021 & $0.172^{\mathrm{AB}}$ & 0.020 & 0.474 & 0.180 \\
\hline$P^{*}$ & 0.000 & & 0.000 & & & \\
\hline
\end{tabular}

C1 $2 \mu \mathrm{g} / \mathrm{mL}$ chlorhexidine and $1 \mu \mathrm{g} / \mathrm{mL}$ nystatin, $C 21 \mu \mathrm{g} / \mathrm{mL}$ chlorhexidine and $0.5 \mu \mathrm{g} / \mathrm{mL}$ nystatin. $S D$ standard deviation

${ }^{*} P$ value for ANOVA comparing the treatments within each concentration; means followed by different letters in the same column differ significantly $(\alpha=0.05)$ by Dunnett's T3 multiple comparisons test Negative control mixed biofilm without drugs; not included in the statistical analysis 
Fig. 2 Optical density (OD) of Streptococcus mutans suspension (A) at C6 (2 $\mu \mathrm{g} / \mathrm{mL}$ chlorhexidine and $1 \mu \mathrm{g} / \mathrm{mL}$ nystatin) and C7 $(1 \mu \mathrm{g} / \mathrm{mL}$ chlorhexidine and $0.5 \mu \mathrm{g} / \mathrm{mL}$ nystatin) and mixed Streptococcus mutans/ Candida albicans biofilm (B) at $\mathrm{C} 1(2 \mu \mathrm{g} / \mathrm{mL}$ chlorhexidine and $1 \mu \mathrm{g} / \mathrm{mL}$ nystatin) and C2 $(1 \mu \mathrm{g} /$ $\mathrm{mL}$ chlorhexidine and $0.5 \mu \mathrm{g} /$ $\mathrm{mL}$ nystatin). Symbols depict the OD mean value for each group and lines represent the standard deviation

\section{A S.mutans suspension}

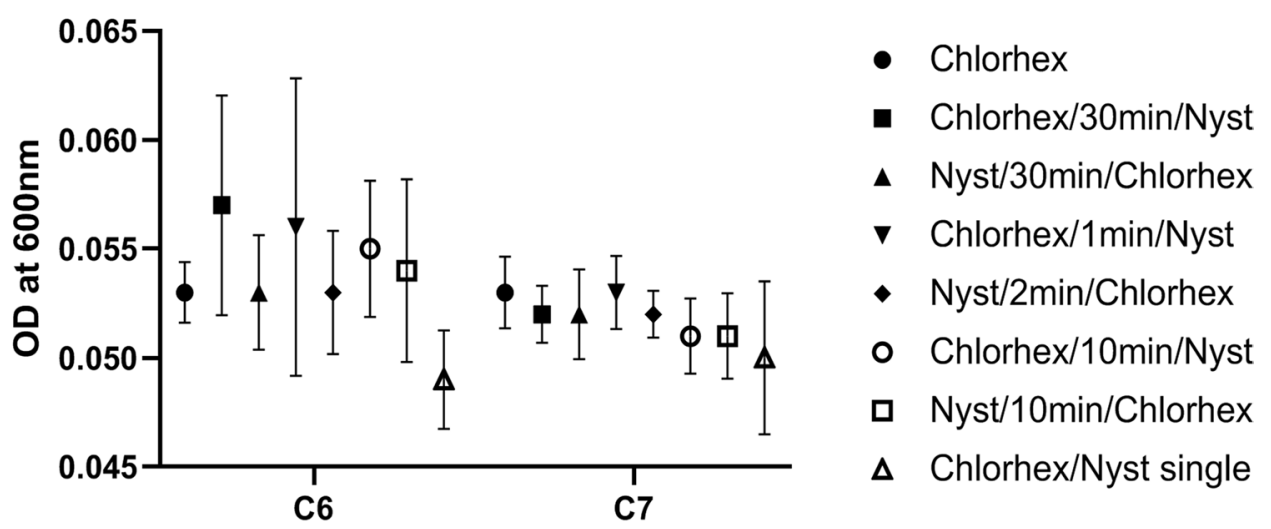

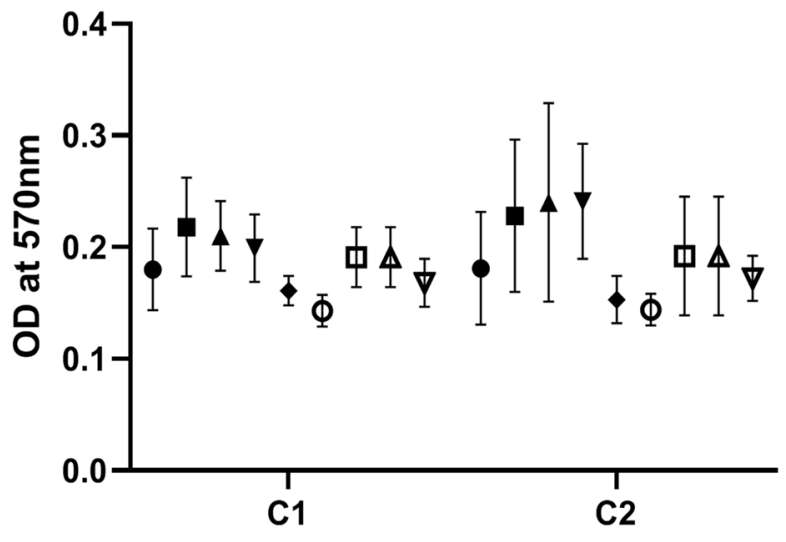

- Chlorhex

- Nyst

- Chlorhex/30min/Nyst

v Nyst/30min/Chlorhex

- Chlorhex/1min/Nyst

- Nyst/2min/Chlorhex

․ Chlorhex/10min/Nyst

$\Delta$ Nyst/10min/Chlorhex

$\boldsymbol{\nabla}$ Chlorhex/Nyst single

means that with this interval, nystatin did not interfere with the action of chlorhexidine or had any effect on S. mutans. The latter inference is quite understandable, since nystatin has no antibacterial properties $[10,11]$. Moreover, our finding suggests that the administration of the drugs with a 30-min interval would be safe. Accordingly, this time interval has already been recommended between chlorhexidine and tooth brushing [22]. Nevertheless, in the biofilm assay, our treatments showed a different performance.

According to the biofilm OD data, the combination of the drugs did not produce significantly different results compared to chlorhexidine alone. Considering its broad spectrum of action, chlorhexidine alone was already expected to be efficacious against $S$. mutans/C. albicans biofilm [3, 4, 30]. On the other hand, the good performance of nystatin/2 min/ chlorhexidine reminds us to the complex structure of the biofilm where an extracellular matrix works as a barrier to antimicrobials [31]. The matrix components are negatively charged and tend to bind positively charged antimicrobials, reducing their diffusion across the biofilm and thus favoring drug resistance [32-34]. It is likely that ionic interactions would occur between the positively charged chlorhexidine molecules and the negatively charged extracellular matrix [35]. Therefore, possibly, the efficacy of nystatin/2 min/chlorhexidine is based on the capability of nystatin to penetrate biofilm and reduce the amount of $C$. albicans, leaving $S$. mutans exposed to chlorhexidine [36]. Accordingly, it was demonstrated that simultaneous use of antimicrobial agents can maximize drug efficacy against Candida biofilm [37].

In comparing CFU counts with biofilm OD, there were some discrepancies, depending on the time-interval used. Overall, chlorhexidine alone showed the best activity against $S$. mutans. Although the single formulation was the worst combination against $C$. albicans, it still showed some activity against $S$. mutans. Among the combinations, the groups using first nystatin and afterwards chlorhexidine tended to show the best results either for $S$. mutans or $C$. albicans. These findings reinforce the idea of an interaction between nystatin and chlorhexidine, where nystatin efficacy is more affected. This corroborates the previous inference about nystatin binding first and killing C. albicans, which would favor chlorhexidine action on $S$. mutans. 
A

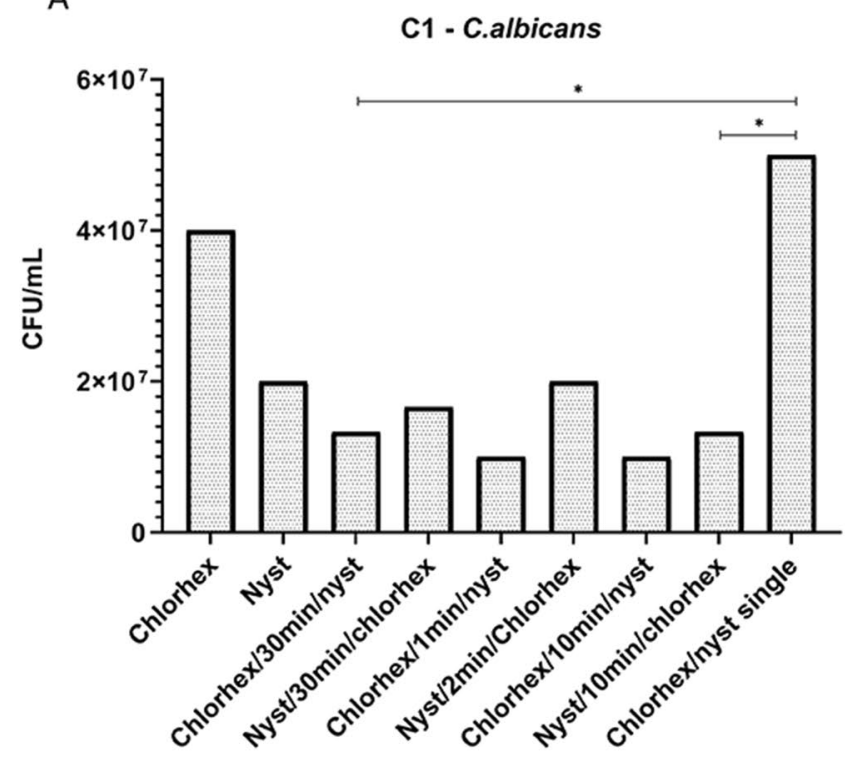

C

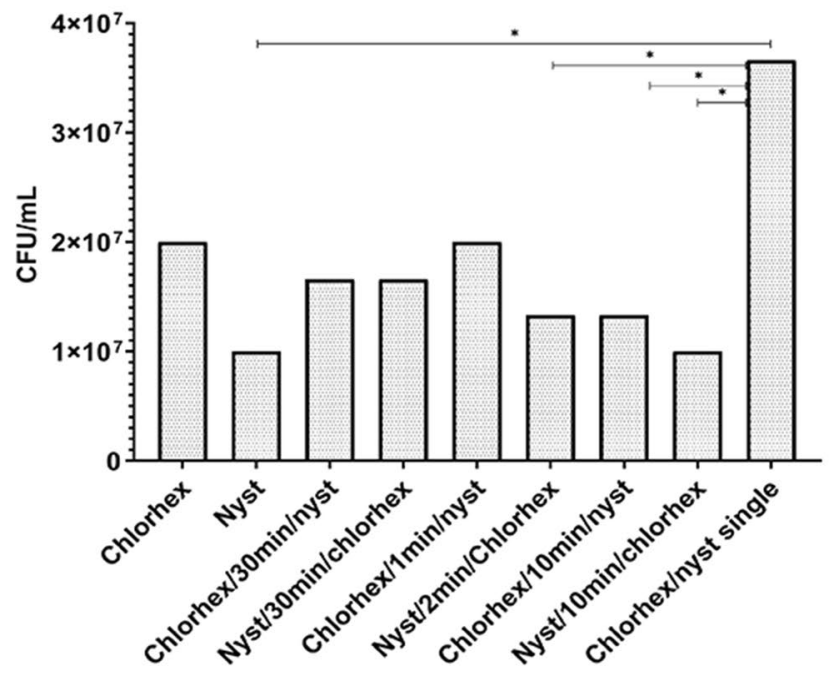

Fig. 3 Colony-forming unit counts (CFU/mL). Images (A) and (B) show the results for $C$. albicans and $S$. mutans, respectively, after treatment with $\mathrm{C} 1(2 \mu \mathrm{g} / \mathrm{mL}$ chlorhexidine and $1 \mu \mathrm{g} / \mathrm{mL}$ nystatin). Images (C) and (D) show the results for C. albicans and S. mutans,

Our suspension growth results suggest that at lower concentrations, the combination of the drugs did not seem to interfere with the antimicrobial effect of chlorhexidine regardless of the time interval used. Accordingly, the findings of Scheibler et al. [17] for C. albicans suspension suggest that at subinhibitory concentrations, the combination of the drugs does not impair their activity, working better than the drugs alone. Najafi et al. [38] investigated the effect of chlorhexidine at 0.12 and $0.2 \%$ on gingival indices and found that lower concentrations worked as well as higher
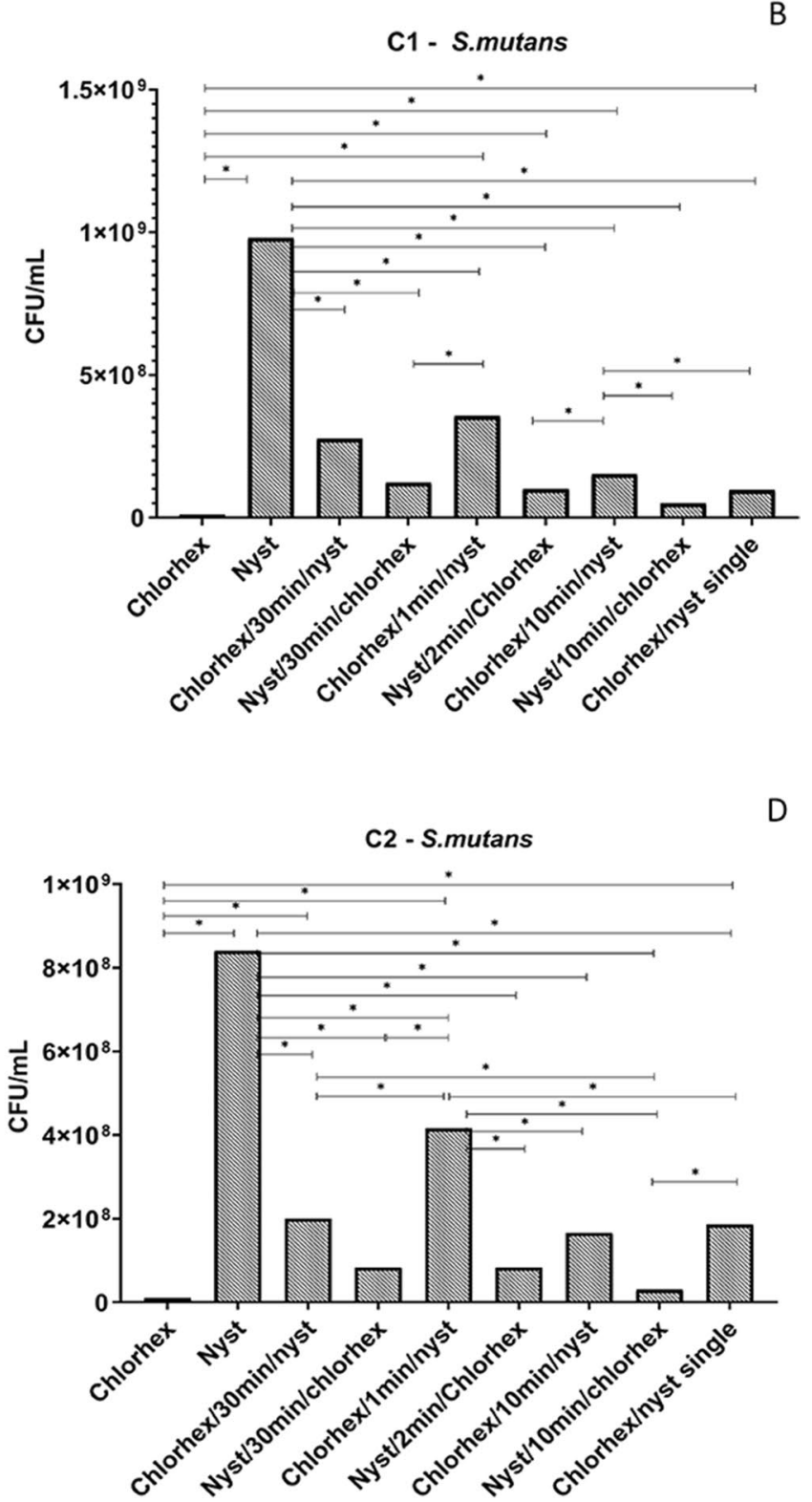

respectively, after treatment with $\mathrm{C} 2(1 \mu \mathrm{g} / \mathrm{mL}$ chlorhexidine and $0.5 \mu \mathrm{g} / \mathrm{mL}$ nystatin). Lines with asterisks indicate where significant differences occurred [ANOVA followed by Dunnett's T3 multiple comparisons test $(\alpha=0.05)]$

ones and with fewer side effects. Moreover, it is probable that the precipitate observed when chlorhexidine and nystatin were combined at the highest concentration corresponds to the salt that Barkvoll and Attramadal [15] reported interfering with the pharmacological effect of the drugs. In our sample, the precipitate occurred in all combinations of the drugs, except in the single formulation. However, another point to ponder is chlorhexidine not showing a classic concentration-dependent effect, when comparing the ODs regarding the increasing concentrations of this agent in the 
broth microdilution assay. A classic study by Nicoletti et al. [39] proposed that chlorhexidine might form precipitates with the medium ingredients, which would explain our data relating to the higher concentrations tested. These authors also observed variability in chlorhexidine MIC with different media. Nonetheless, our study focused the comparisons between the different experimental treatments within each concentration, indicating clear differences for the protocols using chlorhexidine and nystatin, depending on the time of treatment and the order in which either agent was added. The interaction between the drugs is also corroborated by the CDI results, which support the existence of antagonism between them.

Finally, despite the limitations inherent to an in vitro experiment, the findings of the present study support the idea that caution is needed when combining chlorhexidine and nystatin prescriptions in the clinical routine. If possible, this combination should be avoided. This is a major concern regarding immunocompromised and ICU patients, where the best performance of the therapies is crucial. Nevertheless, if there is a situation where concomitant administration of these drugs is, for some reason, mandatory, nystatin should be given first.

\section{Conclusion}

Our results corroborate previous findings showing that chlorhexidine and nystatin can interact with each other. This time though, we found that not only the antifungal but also the antibacterial effect of chlorhexidine can be affected by the combination of the drugs. Nystatin interferes with the action of chlorhexidine against $S$. mutans, and the antimicrobial efficacy of the combined drugs depends on their concentration, time interval used, and the planktonic or biofilm behavior of the microorganisms.

Acknowledgements We thank Dr. A. Leyva (USA) for English editing of the manuscript.

Funding This study was funded in part by the Coordenação de Aperfeiçoamento de Pessoal de Nível Superior-Brasil (CAPES)—Finance Code 001.

\section{Declarations}

Ethics approval This study was approved by the Scientific Committee of School of Health and Life Sciences of the Pontifical Catholic University of Rio Grande do Sul (PUCRS, protocol \#8949). This article does not contain any studies with human participants or animals performed by any of the authors.

Informed consent For this type of study, formed consent is not required.
Conflict of interest The authors declare no competing interests.

\section{References}

1. Wade WG (2013) The oral microbiome in health and disease. Pharmacol Res 69:137-143. https://doi.org/10.1016/j.phrs.2012. 11.006

2. Ramla S, Sharma V, Patel M (2016) Influence of cancer treatment on the Candida albicans isolated from the oral cavities of cancer patients. Support Care Cancer 24:2429-2436. https://doi.org/10. 1007/s00520-015-3035-8

3. Emilson CG (1977) Susceptibility of various microorganisms to chlorhexidine. Eur J Oral Sci 85:255-265. https://doi.org/10. 1111/j.1600-0722.1977.tb00561.x

4. Varoni E, Tarce M, Lodi G, Carrassi A (2012) Chlorhexidine (CHX) in dentistry: state of the art. Minerva Stomatol 61:399-419

5. Hennessey TD (1973) Some antibacterial properties of chlorhexidine. J Periodontal Res 8:61-67

6. Banting DW, Papas A, Clark DC et al (2000) The effectiveness of $10 \%$ chlorhexidine varnish treatment on dental caries incidence in adults with dry mouth. Gerodontology 17:67-76. https://doi. org/10.1111/j.1741-2358.2000.00067.x

7. Gomes BPFA, Vianna ME, Zaia AA et al (2013) Chlorhexidine in endodontics. Braz Dent J 24:89-102. https://doi.org/10.1590/ 0103-6440201302188

8. Scheibler E, Garcia MCR, Medina da Silva R, et al (2017) Use of nystatin and chlorhexidine in oral medicine: properties, indications and pitfalls with focus on geriatric patients. Gerodontology 34.https://doi.org/10.1111/ger.12278

9. Villar CC, Pannuti CM, Nery DM et al (2016) Effectiveness of intraoral chlorhexidine protocols in the prevention of ventilatorassociated pneumonia: Meta-analysis and systematic review. Respir Care 61:1245-1259. https://doi.org/10.4187/respcare. 04610

10. Brescansin EG, Portilho M, Teixeira Pessine FB (2013) Physical and chemical analysis of commercial nystatin. Acta Sci Health Sci 35:215-221. https://doi.org/10.4025/actascihealthsci.v35i2.12769

11. Gunderson SM, Hoffman H, Ernst EJ et al (2000) In vitro pharmacodynamic characteristics of nystatin including time-kill and postantifungal effect. Antimicrob Agents Chemother 44:28872890. https://doi.org/10.1128/AAC.44.10.2887-2890.2000

12. Ellepola ANB (2005) Oral candidosis : a brief overview. Bull Kuwait Inst Med Spec 4:17-24

13. Lyu X, Zhao C, Yan ZM, Hua H (2016) Efficacy of nystatin for the treatment of oral candidiasis: a systematic review and metaanalysis. Drug Des Devel Ther 10:1161-1171. https://doi.org/10. 2147/DDDT.S100795

14. Reis CP, Roque LV, Baptista M, Rijo P (2016) Innovative formulation of nystatin particulate systems in toothpaste for candidiasis treatment. Pharm Dev Technol 21:282-287. https://doi.org/10. 3109/10837450.2014.999783

15. Barkvoll P, Attramadal A (1989) Effect of nystatin and chlorhexidine digluconate on Candida albicans. Oral Surg Oral Med Oral Pathol 67:279-281. https://doi.org/10.1016/0030-4220(89) 90354-X

16. Gaibi M (2006) Formation of salts. Br Dent J 200:62. https://doi. org/10.1038/sj.bdj.4813178

17. Scheibler E, da Silva RM, Leite CE et al (2018) Stability and efficacy of combined nystatin and chlorhexidine against suspensions and biofilms of Candida albicans. Arch Oral Biol 89:70-76. https://doi.org/10.1016/j.archoralbio.2018.02.009

18. CLSI (2008) Reference method for broth dilution antifungal susceptibility testing of yeasts: approved standard, 3rd edn. CLSI 
document M27-A3. Clinical and Laboratory Standards Institute, Wayne

19. CLSI (2019) Performance standards for antimicrobial susceptibility testing. CLSI Supplement M100, 29th edn. CLSI document. Clinical and Laboratory Standards Institute, Wayne

20. Carrillo-Muñoz AJ, Quindós G, Tur C et al (1999) In-vitro antifungal activity of liposomal nystatin in comparison with nystatin, amphotericin B cholesteryl sulphate, liposomal amphotericin B, amphotericin B lipid complex, amphotericin B desoxycholate, fluconazole and itraconazole. J Antimicrob Chemother 44:397-401. https://doi.org/10.1093/jac/44.3.397

21. Sharma S, Khan IA, Ali I et al (2009) Evaluation of the antimicrobial, antioxidant, and anti-inflammatory activities of hydroxychavicol for its potential use as an oral care agent. Antimicrob Agents Chemother 53:216-222. https://doi.org/10.1128/AAC. 00045-08

22. DePaola L, Spolarich E (2007) Safety and efficacy of antimicrobial mouthrinses in clinical practice. Access 81:13-25

23. Harriott MM, Noverr MC (2009) Candida albicans and Staphylococcus aureus form polymicrobial biofilms: effects on antimicrobial resistance. Antimicrob Agents Chemother 53:3914-3922. https://doi.org/10.1128/AAC.00657-09

24. Ibarra-Trujillo C, Villar-Vidal M, Gaitán-Cepeda LA et al (2012) Ensayo de formación y cuantificación de biopelículas mixtas de Candida albicans y Staphylococcus aureus. Rev Iberoam Micol 29:214-222. https://doi.org/10.1016/j.riam.2012.02.003

25. Fernandes RA, Monteiro DR, Arias LS et al (2016) Biofilm formation by Candida albicans and Streptococcus mutans in the presence of farnesol: a quantitative evaluation. Biofouling 32:329-338. https://doi.org/10.1080/08927014.2016.1144053

26. Mattiello SP (2015) Characterization of polymicrobial biofilms of Candida parapsilosis with Staphylococcus aureus or Acinetobacter sp. and evaluation of their susceptibility to sanitizers and antimicrobial drugs. Dissertation, Pontifical Catholic University of Rio Grande do Sul (PUCRS). https://tede2.pucrs.br/tede2/handle/tede/ 6332

27. Goto RN, Sobral LM, Stringhetta-Padovani K, Garcia CB, da Silva G, Vitek MP, Leopoldino AM (2020) Synergic effect of OP449 and FTY720 on oral squamous cell carcinoma. Eur J Pharmacol 882:173268. https://doi.org/10.1016/j.ejphar.2020.173268

28. Ellepola K, Liu Y, Cao T et al (2017) Bacterial GtfB augments Candida albicans accumulation in cross-kingdom biofilms. J Dent Res 96:1129-1135. https://doi.org/10.1177/0022034517714414

29. Peters BM, Jabra-Rizk MA, Scheper MA et al (2010) Microbial interactions and differential protein expression in Staphylococcus aureus -Candida albicans dual-species biofilms. FEMS Immunol Med Microbiol 59:493-503. https://doi.org/10.1111/j.1574-695X. 2010.00710.x

30. Balagopal S, Arjunkumar R (2013) Chlorhexidine: the gold standard antiplaque agent. J Pharm Sci Res 5:270-274

31. Williams D, Lewis M (2011) Pathogenesis and treatment of oral candidosis. J Oral Microbiol 3:1-12. https://doi.org/10.3402/jom. v3i0.5771

32. Donlan RM (2002) Biofilms: microbial life on surfaces. Emerg Infect Dis 8:881-890. https://doi.org/10.3201/eid0809.020063

33. Gordon CA, Hodges NA, Marriott C (1988) Antibiotic interaction and diffusion through alginate and exopolysaccharide of cystic fibrosis-derived pseudomonas aeruginosa. J Antimicrob Chemother 22:667-674. https://doi.org/10.1093/jac/22.5.667

34. Nichols WW, Dorrington SM, Slack MPE, Walmsley HL (1988) Inhibition of tobramycin diffusion by binding to alginate. Antimicrob Agents Chemother 32:518-523. https://doi.org/10.1128/ AAC.32.4.518

35. Shen Y, Stojicic S, Haapasalo M (2011) Antimicrobial efficacy of chlorhexidine against bacteria in biofilms at different stages of development. J Endod 37:657-661. https://doi.org/10.1016/j.joen. 2011.02.007

36. Da Silva WJ, Gonçalves LM, Seneviratne J et al (2012) Exopolysaccharide matrix of developed Candida albicans biofilms after exposure to antifungal agents. Braz Dent J 23:716-722. https:// doi.org/10.1590/S0103-64402012000600016

37. Tonon CC, Francisconi RS, Bordini EAF et al (2018) Interactions between terpinen-4-ol and nystatin on biofilm of Candida albicans and Candida tropicalis. Braz Dent J 29:359-367. https://doi.org/ 10.1590/0103-6440201802073

38. Najafi MH, Taheri M, Mokhtari MR et al (2012) Comparative study of $0.2 \%$ and $0.12 \%$ digluconate chlorhexidine mouth rinses on the level of dental staining and gingival indices. Dent Res J (Isfahan) 9:305-308

39. Nicoletti G, Boghossian V, Gurevitch F et al (1993) The antimicrobial activity in vitro of chlorhexidine, a mixture of isothiazolinones ("Kathon" CG) and cetyl trimethyl ammonium bromide (CTAB). J Hosp Infect 23:87-111. https://doi.org/10.1016/01956701(93)90014-Q

Publisher's note Springer Nature remains neutral with regard to jurisdictional claims in published maps and institutional affiliations. 